\title{
(ㅁ) ]

\section{AVALIAÇÃO DA VIBRAÇÃO NO POSTO OPERACIONAL DE TRATORES COM BAIXA POTENCIA NOMINAL NO MOTOR}

\section{EVALUATION OF VIBRATION IN THE OPERATING STATION OF TRACTORS WITH LOW NOMINAL POWER IN THE ENGINE}

\author{
DOIMO, Lucas da Silva (1) \\ MORAES, Guilherme Aparecido Gomes (2) \\ SANTOS, João Eduardo Guarnetti (3) \\ ANDREOLI, André Luiz (4)
}

(1) Faculdade de Ciências Agronômicas - Unesp, Graduação em Agronomia.

E-mail: lucasdoimo@yahoo.com.br

(2) Faculdade de Ciências Agronômicas - Unesp, Graduação em Agronomia.

E-mail: gomesdemoraes@gmail.com

(3) Faculdade de Engenharia de Bauru - Unesp, Doutorado em Agronomia.

E-mail: guarneti@feb.unesp.br

(4) Faculdade de Engenharia de Bauru - Unesp, Doutorado em Engenharia Elétrica

E-mail: andreoli@feb.unesp.br

\section{RESUMO}

\begin{abstract}
A utilização de máquinas agrícolas na atualidade é uma atividade que tornou-se comum já que a utilização das mesmas tornou-se praticamente indispensável não só no meio rural mas também no meio industrial. A saúde dos operadores destas máquinas tem sido levada mais em consideração nos últimos anos, deste modo, foi conduzido na Faculdade de Ciências Agronômicas - Unesp de Botucatu-SP um delineamento inteiramente casualizado com o objetivo de avaliar a vibração no posto operacional de tratores com baixa potência nominal no motor. De acordo com as avaliações de campo uma das máquinas apresentou problema de vibração excessiva e não atendeu os requisitos mínimos estabelecidos pela diretiva europeia, a outra máquina enquadrou-se no nível de ação e necessita de medidas imediatas para amenizar a vibração. Concluiu-se que é necessário reavaliar o posto operacional de uma das máquinas para reduzir-se o nível de vibração que o operador está exposto e no posto operacional da outra máquina adotar algumas medidas de prevenção para proteger o operador da vibração.
\end{abstract}

Palavras-chave: Trator, Vibração, Operador, Saúde, Segurança. 


\section{(C) 1 (150}

ABSTRACT

The use of agricultural machinery at present is an activity that became common since the use of it became practically essential not only in the rural environment but also in the industrial environment. The health of the operators of these machines has been taken more into account in the last years, in this way, was conducted in the Faculty of Agronomic Sciences - Unesp from Botucatu - SP a completely randomized design with the objective of evaluate the vibration at the operational post of tractors with low nominal power in the engine. In accordance with the evaluations one of the machines presented problem of excessive vibration and did not attend the least requisites established by the European Directive, another machine one fitted in the level of action and it needs immediate measures to ease the vibration. It was concluded that is necessary to re-value the operational post of one of the machines in order that the level of vibration to be reduced that the operator is exposed and in the operational post of another machine to adopt some measures of prevention to protect the operator of the vibration.

Keywords: Tractor, Vibration, Operator, Health, Safety.

\section{INTRODUÇÃO}

Ergonomia é o estudo sobre o relacionamento entre o homem, seu trabalho, equipamento e ambiente. Este estudo envolve a aplicação de conhecimentos sobre anatomia, fisiologia e psicologia na solução dos problemas surgidos deste relacionamento. Numa situação ideal, a ergonomia deve ser aplicada às etapas iniciais do projeto de uma máquina, ambiente ou local de trabalho, visando sempre ao conforto e à segurança do operador (IIDA, 1990). Os parâmetros ergonômicos em máquinas agrícolas não restringem-se somente a disposição dos comandos, o posicionamento do assento, regulagens disponíveis para o assento e comandos, quando refere-se a avaliação de parâmetros ergonômicos inclui-se na avaliação também o ruído e vibração que são produzidos pela máquina.

A operação de equipamentos agrícolas é uma atividade que engloba basicamente dois fatores: o operador e o equipamento. Estes dois fatores interagem entre si, formando o sistema homem-máquina (KROEMER; GRANDJEAN, 2005). Debiasi, Schlosser e Pinheiro (2004) disseram que a eficiência com que o sistema homem-máquina executa suas funções depende de diversos fatores e que a ergonomia age sobre estes fatores, buscando otimizá- los para aumentar a eficiência do sistema de forma a beneficiar o homem, melhorando assim seu rendimento durante a jornada de trabalho e preservando sua saúde.

Os primeiros estudos sobre vibração foram motivados por problemas de desbalanceamento de motores e eixos, o que relata Soeiro (2011) em seu trabalho Vibrações e o Corpo Humano: uma avaliação ocupacional. Por outro lado, Rao (2009) também comentou que a maioria dos motores de acionamento tem problemas de vibração em razão do desbalanceamento inerente aos motores. $O$ autor ainda cita em sua obra, que em muitos sistemas de engenharia, um ser humano age como parte integral do sistema a qual resulta em desconforto e perda de eficiência.

Os tratores que estão em operação, em sua maioria, apresentam problemas de conforto e segurança para os operadores. Em geral, produzem vibrações de baixa frequência, que são transmitidas para o posto do operador e para todas as partes do corpo do trator 


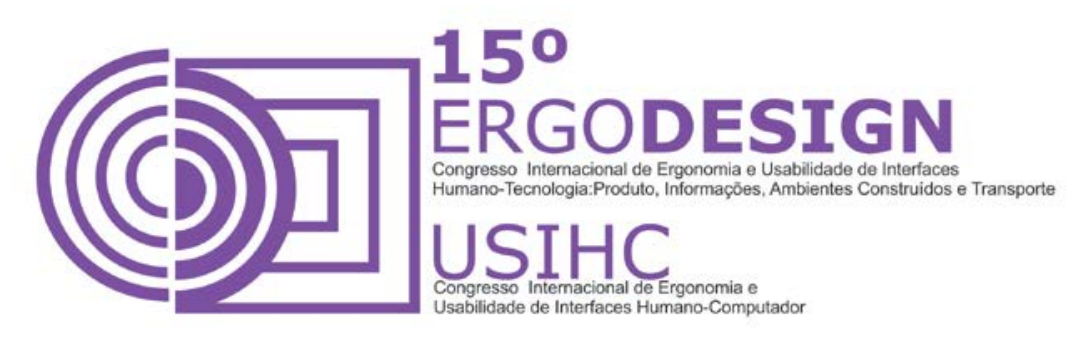

(SERVADIO; MARSILI; BELFIORE, 2007). Estas vibrações podem gerar problemas mecânicos nas partes componentes do trator e também de maneira mais preocupante gerar danos à saúde do operador.

Em vista do exposto, o objetivo do trabalho foi avaliar a vibração no assento do operador de dois tratores agrícolas com baixa potência nominal no motor e verificar se estes estão dentro dos limites estabelecidos nos critérios da EU-OSHA (Agência Europeia para a Segurança e Saúde no Trabalho) e em sua diretiva 44/EC publicada em 22 de Junho de 2002.

\section{MATERIAIS E MÉTODOS}

\subsection{Materiais}

A coleta dos dados nas máquinas foi feita utilizando-se um dosímetro de vibração da marca Larson Davis modelo HVM100, conforme exposto pela Figura 1, devidamente calibrado (calibração realizada em 05/06/2013) e será utilizado o software Blaze, que acompanha o dosímetro, para análise dos dados.

O software Blaze é uma ferramenta para análise de dados e elaboração de relatórios para a higiene e segurança industrial profissionais, através dele simples relatórios transformam-se em poderosas apresentações detalhadas de dados.

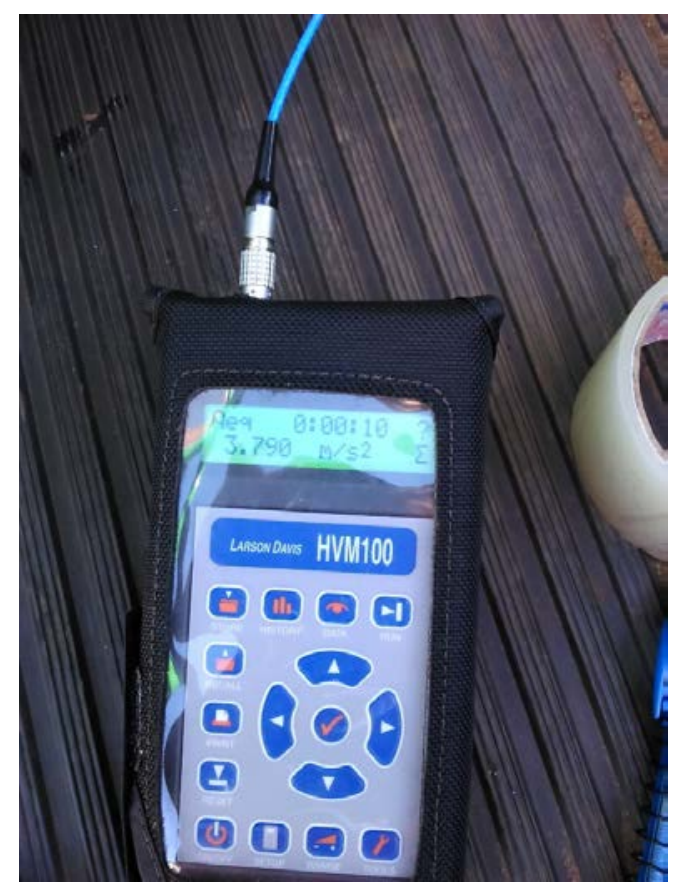

Figura 1. Dosímetro de vibração utilizado para coletar os dados nos tratores.

A vibração será avaliada utilizando-se uma almofada com acelerômetro triaxial (set pad) que pode ser vista na Figura 2, também devidamente calibrado (calibração realizada em 18/04/2013). 

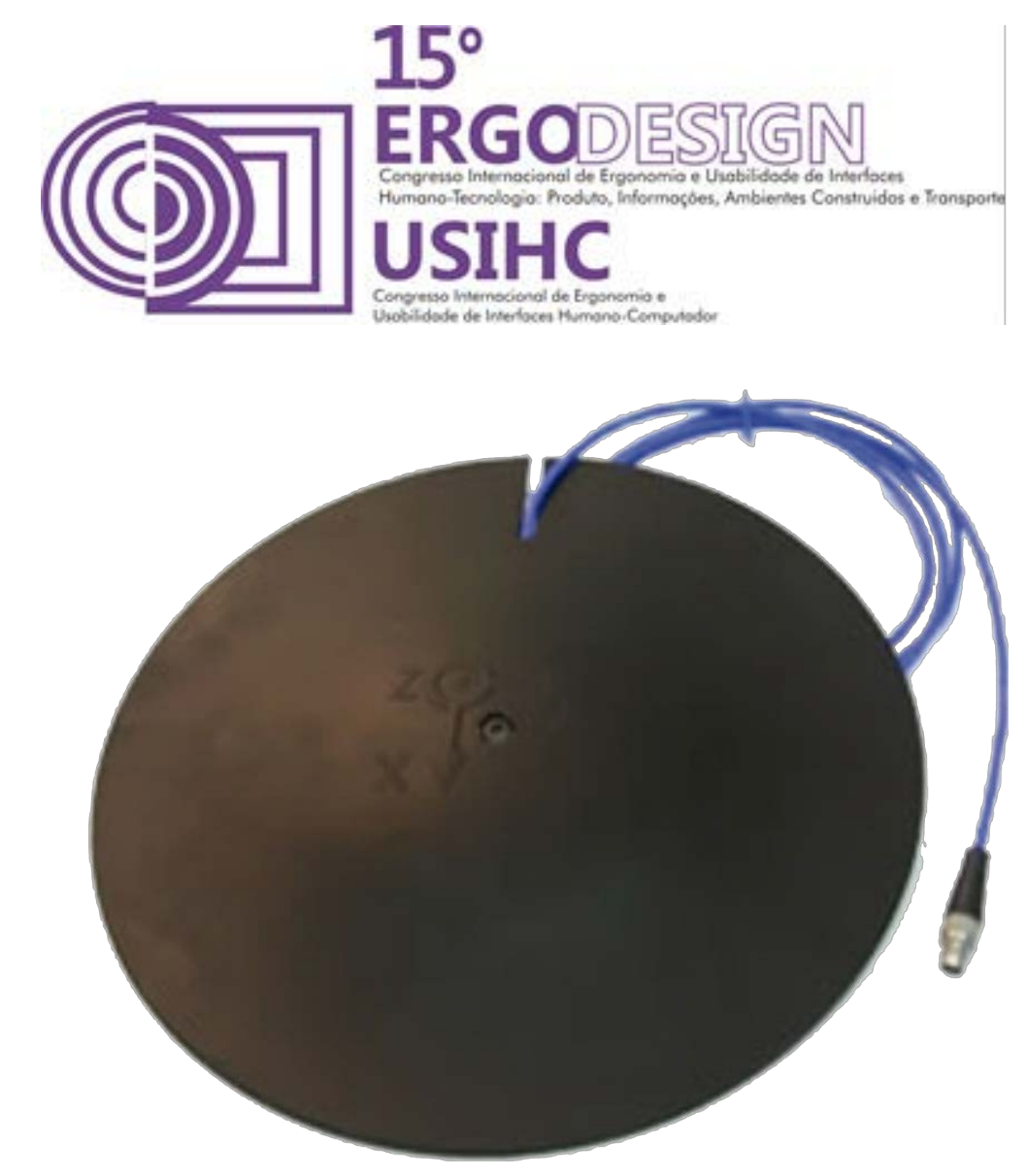

Figura 2. Almofada com acelerômetro triaxial (set pad) utilizada para avaliação da vibração nos tratores.

Para avaliação da vibração foram utilizados dois tratores da marca John Deere com potência nominal no motor distintas, conforme pode ser verificado na Tabela 1. Para facilitar a discussão vamos adotar como sendo o trator 5055E trator "A" e o 5065E trator "B".

Tabela 1. Tratores agrícolas utilizados nas avaliações de vibração.

\begin{tabular}{ccccccc}
\hline Modelo & $\begin{array}{c}\text { Pot. } \\
\text { Nominal } \\
\text { no motor } \\
(\mathrm{kW})\end{array}$ & $\begin{array}{c}\text { Marcha } \\
\text { Lenta } \\
(\mathrm{rpm})\end{array}$ & $\begin{array}{c}\text { Rotação } \\
\text { de } \\
\text { trabalho } \\
(\mathrm{rpm})\end{array}$ & $\begin{array}{c}\text { Horímetro } \\
(\mathrm{h})\end{array}$ & $\begin{array}{c}\text { Rodado } \\
\text { Dianteiro }\end{array}$ & $\begin{array}{c}\text { Rodado } \\
\text { Traseiro }\end{array}$ \\
\hline JD 5055E & 35 & 580 & 2000 & 46 & $\begin{array}{c}9.5-246 \\
\text { Lonas }\end{array}$ & $\begin{array}{c}14.9-286 \\
\text { Lonas }\end{array}$ \\
\hline JD 5065E & 41 & 830 & 2000 & 37 & $\begin{array}{c}11.2-246 \\
\text { Lonas }\end{array}$ & $\begin{array}{c}16.9-2810 \\
\text { Lonas }\end{array}$ \\
\hline
\end{tabular}

\section{$2.2 \quad$ Métodos}

O presente trabalho foi realizado na Faculdade de Ciências Agronômicas - FCA/Unesp em Botucatu - SP localizado nas coordenadas $22^{\circ} 51^{\prime} 25,50^{\prime \prime} \mathrm{S}-48^{\circ} 26^{\prime} 4,48$ "O e à $812 \mathrm{~m}$ acima do nível do mar.

A fixação do set pad no assento das máquinas foi feita de acordo com as exigências contidas na NHO 09, visto na Figura 3. 

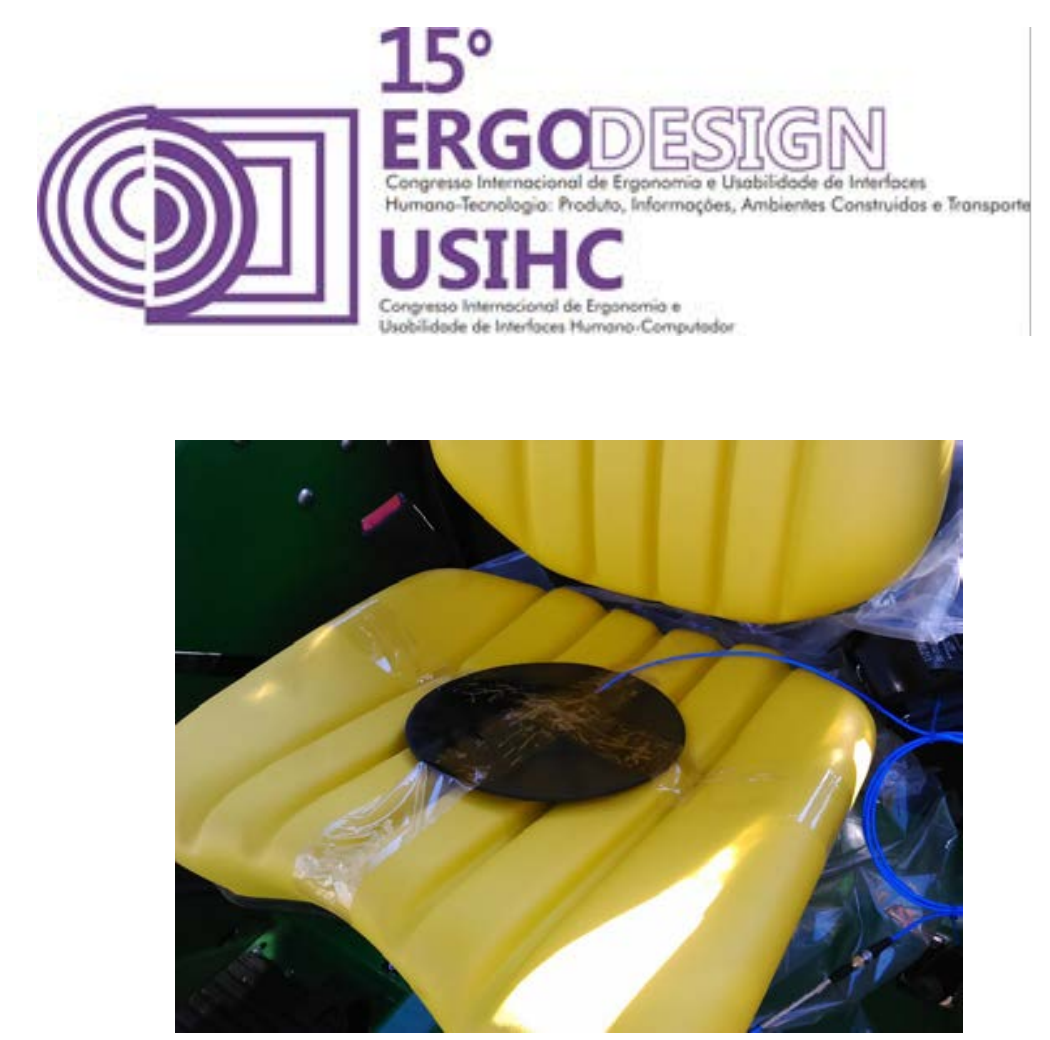

Figura 3. Método utilizado para fixação do set pad na base do assento

Primeiramente foram tomados os devidos cuidados para não haver nada entre o set pad e o assento, como por exemplo no caso dos tratores novos o assento pode vir protegido por um plástico por cima, então este será retirado para que o set pad fique em contato direto com o assento. Sua fixação foi feita com o auxílio de uma fita adesiva para que este não saia da posição inicial da coleta, de modo que em todas as avaliações o set pad esteja sempre no mesmo lugar e também utilizando-se a fita o contato com o banco foi mantido durante toda a avaliação. Em ambos os tratores, a avaliação da vibração foi feita na base do assento e posteriormente o método que foi utilizado na base do assento também foi utilizado para fazer uma avaliação no encosto do assento, observado na Figura 4, desta forma, obteve-se toda a vibração que estava chegando até o assento da máquina.

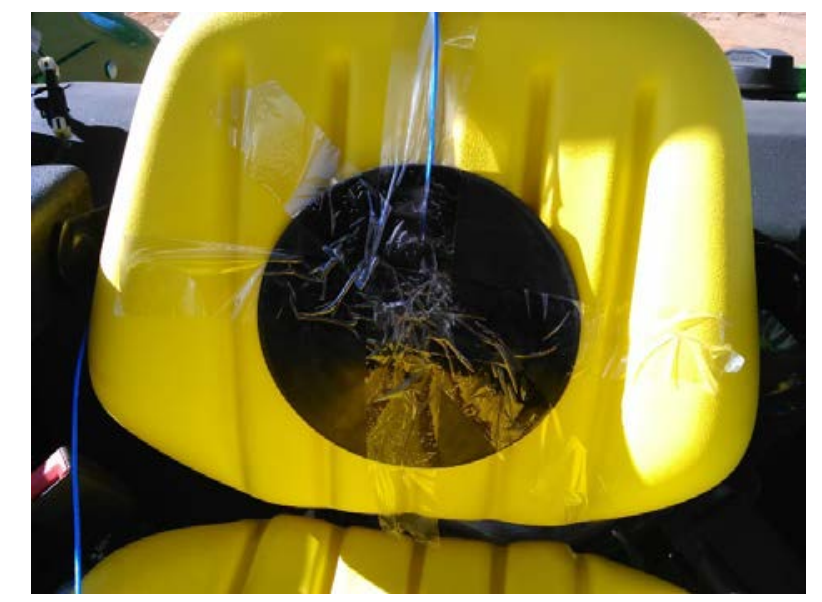

Figura 4. Método de fixação do set pad no encosto do assento.

Os valores coletados na base e no encosto do assento serão somados e feito uma média entre eles e esta será considerada como a vibração total que chega até o assento, já que a mesma é proveniente de dois valores obtidos na avaliação de campo.

Foram feitas cinco repetições, cada repetição teve duração de 1min, neste intervalo de tempo o aparelho foi programado para fazer uma leitura a cada segundo, totalizando assim 60 leituras por repetição. Os valores obtidos nestas avaliações foram confrontados 


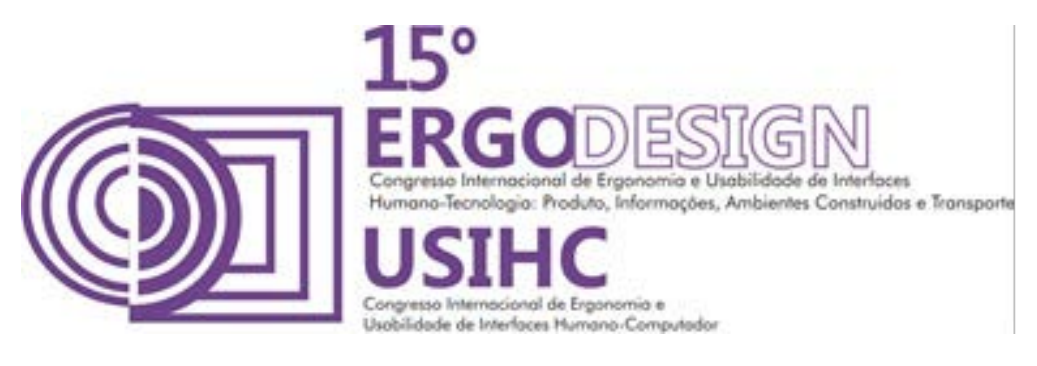

com a diretiva europeia 2002/44/EC e os valores que apresentarem-se superiores a 0,5 $\mathrm{m} / \mathrm{s}^{2}$ para uma exposição diária de $8 \mathrm{~h}(\mathrm{~A}(8)$ ) ou um valor de dose de vibração (VDV) superior a 9,1 m/s1,75 serão enquadrados no nível de ação. Os valores de $A(8)$ que forem superiores a $1,15 \mathrm{~m} / \mathrm{s}^{2}$ ou um valor de VDV maior que $21 \mathrm{~m} / \mathrm{s} 1,75$ serão enquadrados fora das exigências pois estão acima do limite de exposição.

O delineamento experimental utilizado foi inteiramente casualizado, todas as máquinas foram avaliadas no mesmo local. O local da avaliação foi em uma superfície de concreto plana. Foi coletada a vibração dos tratores com o motor funcionando em $2000 \mathrm{rpm}$. Os dados obtidos nas avaliações foram submetidos a uma análise de variância e verificado a significância os mesmos foram comparados pelo teste de tukey ao nível de $5 \%$ de probabilidade.

\section{RESULTADOSE DISCUSSÃO}

Os resultados obtidos na avaliação das máquinas estão expostos na Tabela 2. Através da análise da tabela podemos afirmar que estatisticamente houve diferença entre todos os parâmetros analisados. Observando-se o valor da aceleração média no tempo medido (Aeq), o trator A vibrou mais do que o trator B. O trator $A$ teve seus valores superiores em praticamente todos os parâmetros avaliados, com exceção para o fator de crista (CFmp), com destaque para o valor de dose de vibração (VDV), este por sua vez foi aproximadamente quatro vezes maior do que o valor obtido para o trator B.

Tabela 2. Valores de vibração obtidos em ambas as máquinas com o motor funcionando a 2000rpm.

\begin{tabular}{|c|c|c|c|c|c|c|c|}
\hline Tratamento & $\begin{array}{c}\text { Aeq } \\
\left(\mathrm{m} / \mathrm{s}^{2}\right) \\
\end{array}$ & $\begin{array}{l}\text { Amax } \\
\left(\mathrm{m} / \mathrm{s}^{2}\right) \\
\end{array}$ & $\begin{array}{c}\text { Amp } \\
\left(\mathrm{m} / \mathrm{s}^{2}\right)\end{array}$ & $\begin{array}{l}\text { Amin } \\
\left(\mathrm{m} / \mathrm{s}^{2}\right)\end{array}$ & VDV & $\begin{array}{c}\text { CFmp } \\
(\mathrm{dB})\end{array}$ & $\begin{array}{c}\mathrm{A}(8) \\
\left(\mathrm{m} / \mathrm{s}^{2}\right) \\
\end{array}$ \\
\hline Trator A & $12,364 \mathbf{a}$ & $13,1 \mathbf{a}$ & $20,18 \mathbf{a}$ & $11,595 \mathbf{a}$ & $38,07 \mathbf{a}$ & $4,262 \mathbf{a}$ & $0,5613 \mathbf{a}$ \\
\hline Trator B & $3,521 \mathbf{b}$ & 3,752 b & 6,728 b & $3,343 \mathbf{b}$ & $10,945 \mathbf{b}$ & $5,58 \mathbf{b}$ & $0,1531 \mathbf{b}$ \\
\hline $\begin{array}{l}\text { Média } \\
\text { Geral }\end{array}$ & 7,9425 & 8,426 & 13,454 & 7,469 & 24,5075 & 4,921 & 0,3572 \\
\hline C.V. (\%) & 7,94 & 8,12 & 5,55 & 10,77 & 7,77 & 5,69 & 8,2 \\
\hline
\end{tabular}

${ }^{*}$ médias com letras iguais na coluna não diferem entre si pelo teste de tukey $p<0,05$

Considerando uma jornada de trabalho que comumente são dedicados $8 \mathrm{~h}$ diárias a esta atividade, pode-se observar que a projeção de dose para a jornada de trabalho $(A(8))$ do trator $A$ foi bastante superior ao valor encontrado para o trator $B$, aproximadamente quatro vezes superior.

Confrontando estes valores em questão com a diretiva europeia 44/EC pode-se afirmar que de acordo com o VDV obtido para o trator A, este encontra-se acima do limite de exposição e portanto os operadores desta máquina podem estar prejudicando a sua saúde. 


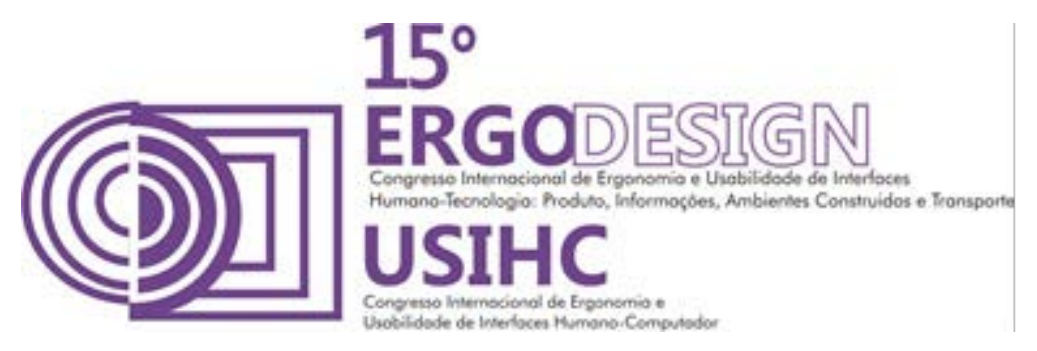

Por outro lado o trator B não está acima do limite de exposição, mas encontra-se dentro do nível de ação e necessita-se a tomada de medidas para amenizar a vibração. Por outro lado considerando o valor obtido de $A(8)$ o trator $A$ enquadra-se dentro do nível de ação e pode trazer riscos à saúde dos operadores, já o trator $\mathrm{B}$ está atendendo as exigências mínimas.

A Figura 5 mostra a vibração coletada nos três eixos ortogonais, através dela pode-se ver como a vibração foi superior no trator $A$ e também como ela teve uma oscilação bastante superior ao contrário do trator $B$ onde a vibração teve um comportamento bem mais harmonioso e com uma quantidade inferior de picos.

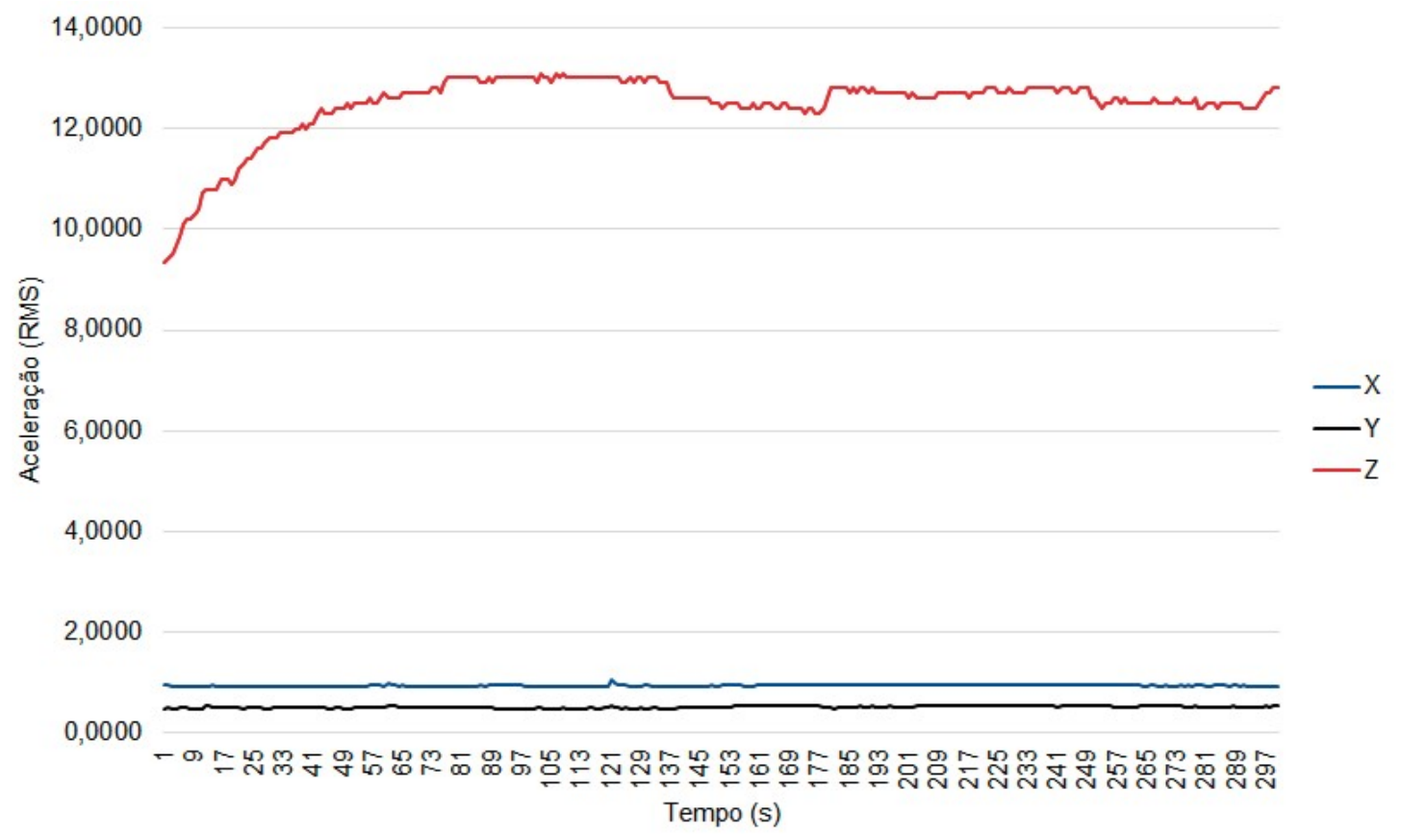

Figura 5. Comportamento da aceleração no assento do trator A nos três eixos ortogonais durante um período de $5 \mathrm{~min}$.

A figura 6 mostra-nos o motivo do trator B ter um CFmp (fator de crista) mais elevado, durante o tempo de coleta a vibração nesta máquina teve uma oscilação bastante alta, mas, mesmo assim a máquina não ultrapassou o limite de exposição e enquadra-se dentro do nível de ação 


\section{(C)] USTIC}
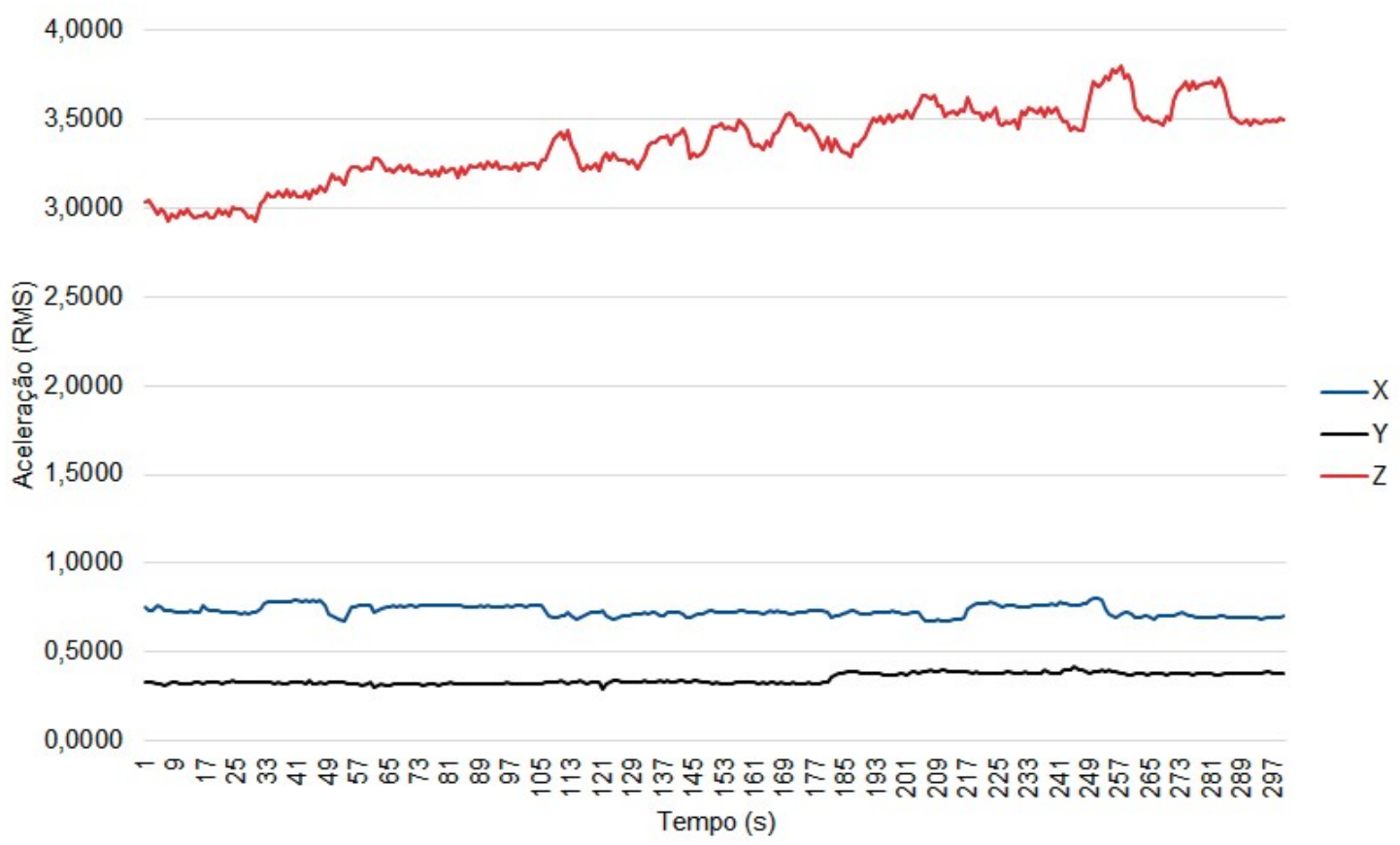

Figura 6. Comportamento da aceleração no assento do trator B nos três eixos ortogonais durante um período de 5 min

Pode-se observar também nas figuras 5 e 6 que onde ocorrem os valores mais elevados de vibração é no sentido do eixo $Z$, vibração esta que atinge a coluna vertebral dos operadores, portanto, pode vir à causar injúrias na coluna dos operadores destas máquinas.

\section{CONCLUSÕES}

Com a realização do trabalho conclui-se que o trator A está fora dos padrões ultrapassando o valor limite de exposição diária normalizada pela diretiva europeia, por outro lado o trator B não ultrapassou o limite de exposição, mas está enquadrado dentro do nível de ação normalizado pela diretiva.

Pode-se concluir também que os maiores níveis de vibração são encontrados no sentido do eixo $Z$.

\section{REFERÊNCIAS BIBLIOGRÁFICAS}

DEBIASI, Henrique; SCHLOSSER, José Fernando; PINHEIRO, Eder Dornelles. Características ergonômicas dos tratores agrícolas utilizados na região central do Rio Grande do Sul. Ciência Rural, Santa Maria, v. 34, n. 6, p.1807-1811, dez. 2004.

IIDA, I. Ergonomia, projeto e produção. São Paulo, Edgard Blucher, 1990. 465p. KROEMER, Karl H. E.; GRANDJEAN, Etienne. Manual de Ergonomia: Adaptando o Trabalho ao Homem. 5. ed. Porto Alegre: Bookman, 2005. 328 p. 


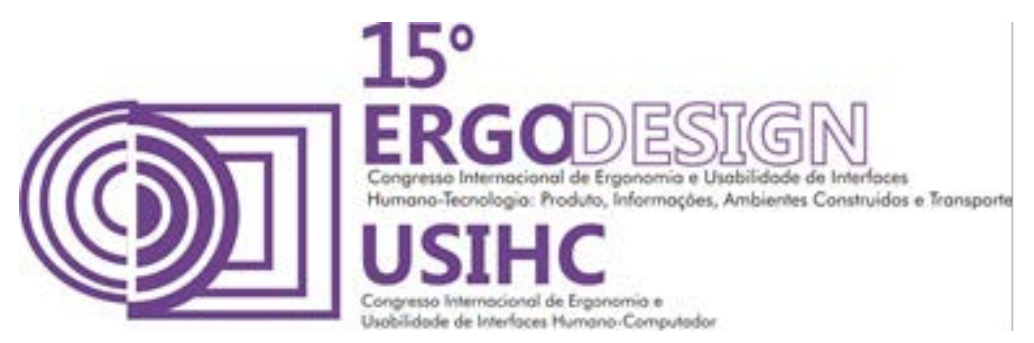

RAO, Singiresu. Vibrações Mecânicas. 4. ed. São Paulo: Pearson, 2009. 448 p.

SERVADIO, P.; MARSILI, A.; BELFIORE, N. P.. Analysis of driving seat vibrations in high forward speed tractors. Biosystems Engineering. Kidlington, p. 171-180. jun. 2007.

SOEIRO, Newton Sure. Vibrações e o Corpo Humano: uma avaliação ocupacional. In: WORKSHOP DE VIBRAÇÕES E ACÚSTICA DA REGIÃO NORTE, 1., 2011, Tucuruí. Palestra. Tucuruí: UFPA, 2011. p. 1 - 10. 